\title{
A ENFERMAGEM COMO ÁREA DE CONHECIMENTO NO CNPq: RESGATE HISTÓRICO DA REPRESENTAÇÃO DE ÁREA
}

\author{
Nursing as an Area of Knowledge in the CNPq: \\ Historical Rescue of the Representation of the Area \\ Enfermería como Área de Conocimiento en el CNPq: \\ Rescate Histórico de la Representación del Área
}

\begin{abstract}
Resumo
0 Conselho Nacional de Desenvolvimento Científico e Tecnológico (CNPq) foi criado em 1951. Neste organismo nacional de apoio à pesquisa, a Enfermagem insere-se como área de conhecimento a partir da década de 70 e passa a ter representante de área desde a década de 80. 0 presente artigo tem como objeto o resgate histórico da Enfermagem como área de conhecimento no CNPq. Objetiva destacar a inserção da Enfermagem neste órgão e contribuição para o conhecimento da História da Enfermagem Brasileira. Trata-se de um estudo documental apoiado por depoimentos das enfermeiras representantes da área de Enfermagem no transcurso da presença da Enfermagem como área no CNPq. As informações descritas mostram a importância e a evolução da Enfermagem como ciência e tecnologia neste órgão, a importância do fomento para viabilização das pesquisas, o estímulo ao incremento da pesquisa, os avanços na produção de conhecimentos, os desafios enfrentados e as perspectivas como possibilidades para o fortalecimento e consolidação da Enfermagem. 0 CNPq é um importante órgão de fomento às políticas para o avanço da Enfermagem.
\end{abstract}

Palavras-chave: Enfermagem. Ciência. Pesquisa em Enfermagem. História da Enfermagem.

\begin{abstract}
The National Council of Scientific and Technological Development (CNPq) was created in 1951. In this national organ of research support, the Nursing is inserted as a knowledge area from 1970's and passed on to an area representative since 1980's. This present article has as object the historical rescue of the Nursing as knowledge area at the CNPq. It aims to detach the Nursing insertion at this organ and its contribution for the knowledge of the Brazilian Nursing History. It is a question about a documentary study supported by depoiments of the representative nurses of the nursing area in the course of the existence of the Nursing as an area at the CNPq. The information described showed the importance and the evolution of the Nursing as science and technology in this organ, the importance of the promotion for making the research viable, the stimulation to the increment of the research, the advances in producing knowledge, the challenges faced and perspectives as possibilities for the strengthening and consolidation of the Nursing. The CNPq is an important agency of promoting politics for the advance of the Nursing.
\end{abstract}

Keywords: Nursing. Science. Nursing Research. History of Nursing.

\section{Resumen}

El Consejo Nacional de Desarrollo Científico y Tecnológico (CNPq) fue creado en 1951. En este organismo nacional de apoyo a la investigación, la Enfermería se inserta como área de conocimiento partiendo de los años 70 y pasa a tener representante de área desde la década de los 80 . El presente artículo tiene como objeto el rescate histórico de la Enfermería como área de conocimiento en el CNPq. Se objetiva destacar la inserción de la Enfermería en este órgano y su contribución para el conocimiento de la Historia de la Enfermería Brasileña. Tratase de un estudio documental apoyado por depoimentos de las enfermeras representantes del área de la Enfermería en el curso de la existencia de la Enfermería como área en el CNPq. Las informaciones descritas muestran importancia y la evolución de la Enfermería como ciencia y tecnología en este órgano, la importancia del fomento para la promoción de las investigaciones, el estímulo al incremento de la investigación, los avances en la producción de conocimientos, los desafíos enfrentados y las perspectivas como posibilidades para el fortalecimiento y consolidación de la Enfermería. El CNPq es un importante órgano de fomento a las políticas para el avance de la enfermería.

Palabras clave: Enfermería. Ciencia. Investigación en Enfermería. História de la Enfermería. 
INTRODUÇÃO:

\section{ASPECTOS HISTÓRICOS SOBRE O CNPq}

O CNPq é uma das maiores e mais sólidas estruturas públicas de apoio à Ciência, Tecnologia e Inovação (CT\&l) dos países em desenvolvimento. A idéia de criar uma entidade governamental específica para fomentar o desenvolvimento cientifico remonta ao ano de 1920, quando os integrantes da Academia Brasileira de Ciências ( $A B C$ ) comentavam o assunto como conseqüência da Primeira Guerra Mundial. Em 1931, a ABC dá a sugestão formal ao governo, e este não se pronuncia a respeito. Em maio de 1936, o presidente Getúlio Vargas enviou uma mensagem específica ao Congresso sobre essa idéia, mas ainda não teve a acolhida desejada por parte dos parlamentares.

A partir da Segunda Guerra Mundial, graças ao avanço das tecnologias bélica, aérea e farmacêutica, houve um despertar não só no Brasil, mas em todos os países, para a importância da investigação científica principalmente em energia nuclear. A bomba atômica era a prova real e assustadora do poder que a ciência poderia atribuir ao homem, ficando claro como a pesquisa deveria passar a ser vista pelos governos. Seria uma área a ser alvo de investimento, principalmente se fosse acompanhada de uma agenda de prioridades enfocando problemas de difícil resolução, ou ainda, se significasse desenvolvimento científico e tecnológico.

Depois desses esforços, em maio de 1946, o Almirante Alberto da Motta e Silva, representante brasileiro na Comissão de Energia Atômica do Conselho de Segurança da recém-criada Organização das Naç̃es Unidas (ONU), propôs ao governo, por intermédio da $\mathrm{ABC}$, a criação do $\mathrm{CNPq}$, denominado na época Conselho Nacional de Pesquisa. Dois anos mais tarde, em 1948, o projeto sobre a criação do CNPq era apresentado à câmara dos Deputados. Porém, somente em 1949, o presidente Eurico Gaspar Dutra indicou uma Comissão para apresentar um anteprojeto de lei sobre a sua criação. Depois de discutido em diversas comissões, em 15 de janeiro de 1951, foi criado o CNPq, pela Lei $n^{0} 1310 / 51$, chamada pelo Almirante Álvaro Alberto de Lei Áurea da Pesquisa do Brasil1'.

0 Conselho Nacional de Pesquisas, fundado em 1951, pelo cientista pesquisador de energia atômica Álvaro Alberto, como órgão diretamente subordinado à Presidência da República, decorreu da necessidade de evitar a desapropriação das nossas reservas de material radioativo. Em 1964, o Conselho teve ampliada sua área de competência, incluindo a formulação e coordenação da política científica e tecnológica do país, deixando de ser sua competência as pesquisas no campo da energia atômica. A partir de 1972 surgem os Planos Básicos de Desenvolvimento Científico e Tecnológico (PBDCTs) integrados aos Planos Nacionais de Desenvolvimento (PNDs).

Em 1974, 0 Conselho torna-se fundação de direito privado, com a denominação de Conselho Nacional de Desenvolvimento Científico e Tecnológico, vinculado a Secretaria de Planejamento da Presidência da República (SEPLAN) e, posteriormente, à Secretaria de Ciência e Tecnologia ligada diretamente à Presidência da República com o objetivo de modernização científica e tecnológica do país'.
0 Conselho Nacional de Desenvolvimento Científico e Tecnológico, que conserva a mesma sigla, vem assumindo maiores proporções. É uma Fundação, vinculada ao Ministério da Ciência e Tecnologia (MCT), cuja missão é apoiar a pesquisa brasileira. Contribuindo diretamente para a formação de pesquisadores (mestres, doutores, pós-doutores e especialistas em várias áreas de conhecimento), o CNPq é, desde sua criação até hoje, uma das maiores e mais sólidas estruturas públicas de apoio à Ciência, Tecnologia e Inovação (CTI) dos países em desenvolvimento cujos investimentos são direcionados para a formação e absorção de recursos humanos e financiamento de projetos de pesquisa que contribuem para o aumento da produção de conhecimento e geração de novas oportunidades de crescimento para o país ${ }^{1}$.

Estes investimentos resultam na identificação de novos talentos pelas atividades de iniciação científica com bolsas (IC); no apoio ao trabalho do pesquisador com bolsa de produtividade em pesquisa $(\mathrm{PQ})$ e na manutenção do sistema Lattes de registro do curriculum vitae; no apoio aos Grupos de Pesquisa - Cadastrados no Diretório de Grupos de Pesquisa, no fortalecimento das Linhas de Pesquisa, na viabilização de Políticas e Prioridades em Pesquisa, dentre outros².

Este estudo tem como objeto o resgate da Enfermagem como área de conhecimento no CNPq. E como objetivos: (a) destacar a origem da inserção da Enfermagem como área de conhecimento no CNPq e sua contribuição para a profissão; e (b) contribuir para o conhecimento da História da Enfermagem Brasileira.

\section{A ENFERMAGEM COMO ÁREA DE CONHECIMENTO}

Somente a partir de 1970 é que se efetivaram as primeiras medidas de apoio em relação à Enfermagem. A evolução histórica dessas medidas transcorreu da seguinte maneira:

a) Realização do primeiro evento "Avaliação e Perspectiva - Subárea de Enfermagem" em 1976;

b) Em 1980 foi criado o código da Subárea de Enfermagem com suas subespecialidades, no sistema de classificação das áreas de conhecimento no CNPq; c) Em 1981/1982 foi realizada a segunda versão do evento "Avaliação e Perspectiva - subárea de Enfermagem";

d) Em 1984 foi iniciada a formação do quadro de Consultores "Ad hoc" para apreciar os projetos, como subsídio ao corpo técnico e ao Comitê Assessor de Clínica (CA-CL) do CNPq, local onde esta subárea estava localizada.

Realizou-se, assim, a concretização de duas recomendações contidas no documento da segunda "Avaliação e Perspectiva", ou seja, a de existir um representante da subárea de Enfermagem como membro efetivo no Comitê Assessor de Clínica do CNPq e de um assessor técnico de desenvolvimento científico atuando na instituição, situações estas regularizadas a partir de $1986^{3}$ Depois deste, foi constituído o Comitê Assessor de "Saúde Complementar" composto pelas áreas de 
Odontologia, Enfermagem e Educação Física, que foi desmembrado do CA de Medicina II ${ }^{4}$.

Portanto, vimos que, muito embora o CNPq tenha sido criado em 1951, a Enfermagem somente foi incluída como área de conhecimento em 1986, em razão dos esforços de uma professora da Universidade de Brasília, que compunha o quadro de técnicos da estrutura da agência ${ }^{4}$.

Esta inserção da Enfermagem como área de conhecimento em 1986 coincide com os frutos do primeiro doutoramento em Enfermagem do Brasil - o Curso de Doutorado Interunidades em Enfermagem de responsabilidade das duas Escolas de Enfermagem da USP - Universidade de São Paulo: uma localizada no Campus da Capital (EEUSP); e outra localizada no Campus de Ribeirão Preto (EERP-USP) 5 .

Em sua evolução, por três vezes o CNPq reformulou sua organização estrutural, e a Enfermagem consolidouse como área de produção de conhecimento fazendo jus ao direito de se inserir em um Comitê Assessor: o CA de Medicina II. No ano de 1991 foi criado o Comitê de Saúde Complementar para o qual a Enfermagem foi transferida. Este Comitê recebeu nova denominação em 1995: Comitê Multidisciplinar de Saúde (CA-MS) constituído pelas Subáreas da Educação Física, Enfermagem, Fisioterapia, Terapia Ocupacional, Fonoaudiologia e Odontologia.

Em julho de 2005, a Odontologia é desmembrada constituindo sozinha um novo Comitế. E, em outubro de 2006, ocorreu o marco histórico do Comitê: a implantação do Comitê de Enfermagem (CA-EF), aprovado pelo Conselho Deliberativo do CNPq, em junho de 2006. A indicação de seus membros (três membros titulares e um suplente) foi aprovada na mesma instância em 20 de setembro de 2006, tendo sua implantação ocorrido no dia primeiro do mês de outubro. Esta foi uma grande conquista da profissão e fruto do esforço coletivo. 0 CA-EF reuniu-se pela primeira vez em Brasília no período de 20 a 24 de novembro de 2006, com a presença das representantes titulares. Neste período os trabalhos do Comitê foram coordenados pela representante com maior tempo de exercício de representação ${ }^{6}$.

Os Comitês Assessores têm por objetivo prestar assessoria ao CNPq na avaliação de projetos e programas, na formulação de políticas em assuntos de sua área de competência e na apreciação das solicitações de apoio à pesquisa e à formação de recursos humanos. Analisam, ainda, as solicitações de bolsas e auxilios pronunciando-se mediante pareceres fundamentados e conclusivos sobre o mérito dos mesmos. Para tal, contam com auxílio de consultores ad hoc?

Desde a instituição da Representação da Área da Enfermagem no CNPq, seis professoras doutoras foram responsáveis pela mesma e serviram como assessoras, ocupando a função de Representante e contribuindo significativamente para o processo de incremento à pesquisa em Enfermagem, incentivando a produção de projetos com condições de concorrer a financiamentos, ao tempo em que, internamente tornam a Enfermagem mais conhecida pelo órgão ${ }^{7}$

\section{A BUSCA DE INFORMAÇÕES SOBRE A ÁREA DE ENFERMAGEM NO CNPq}

Para o alcance dos objetivos estabelecidos no presente estudo, selecionou-se um estudo documental de caráter qualitativo, apoiado por depoimentos orais obtidos no período de março a junho de 2005 e consentidos pelas enfermeiras representantes da área de Enfermagem. Esses depoimentos exploraram o transcurso das suas presenças na área, no CNPq. Os principais aspectos abordados nos depoimentos centraram-se em dados como: formação (níveis, títulos, anos, escolas); período de atuação como Representante da Enfermagem no CNPq, composição do CA segundo áreas, identificação do processo de indicação; principais atividades realizadas e avanços obtidos para a área; parecer sobre a própria experiência de ser representante da área da Enfermagem no CNPq; indicação dos aspectos mais marcantes da experiência vivenciada; o significado do CNPq para a Enfermagem Brasileira; e a Enfermagem como profissão e como ciência e suas principais conquistas, dentre outros aspectos.

A coleta e análise das informações e de dados constaram da busca de documentos disponíveis no site do CNPq, relatórios e artigos publicados, bem como dos depoimentos, observadas as seguintes etapas: (a) consulta às ex-representantes sobre a possibilidade de informarem sobre sua participação nesta representação, o que foi aceito por todas; e (b) a compilação de documentos com conteúdos sobre o tema explorado. Participaram deste estudo todas as cinco ex-representantes e a representante atual, mediante consentimento verbal das mesmas para utilização de seus depoimentos neste artigo.

\section{SÍNTESE DOS PRINCIPAIS RESULTADOS:}

As informações obtidas permitiram descrever sobre: os períodos de atuação das representantes, principais atividades realizadas, os avanços da área e, em especial, como foi a experiência de ser Representante da Área da Enfermagem no CNPq.

A) O PERÍODO DE ATUAÇÃO DAS REPRESENTANTES é anal isado como se segue:

A representação da área inicialmente foi de dois anos, e de 1990 em diante passou para três anos, e é indicada pelo CNPq a partir de consulta aos pesquisadores com bolsa de produtividade em pesquisa, sugeridos entre os mais qualificados. 0 início desta representação foi marcado por buscas não só de espaços, mas também de conquista de igualdades.

À minha época, o comitê denominava-se "Medicina II", e, por não concordar com a maneira como apreciados os pleitos no Comitê, fui substituída, portanto o meu mandato foi de 1988 a 1989 (Depoente 1).

Neste depoimento percebe-se ainda a vulnerabilidade da Enfermagem na Agência, apesar dos esforços para colocá-la na mesma condição das outras áreas. Também, as conquistas por espaços e maior visibilidade e exclusividade são marcadas quando foi conseguido o desmembramento da Medicina II, área tradicional e consolidada.

Eleita pela comunidade científica, atuei no Comitê Assessor de Saúde Complementar, no período 1990 - 
1992. No meu mandato foi desmembrado o CA de Medicina Il e criado o de Saúde Complementar (Depoente 2).

A escolha da representante é prerrogativa da Presidência, que consulta a comunidade científica, analisa o currículo dos recomendados e então procede a indicação.

Estive na agência no período de 1993-1995. A indicação foi pelo Conselho Diretor, após consulta à comunidade científica e análise dos currículos em apreço. Na ocasião era uma das três (3) pesquisadoras da área de nível 1 A. ... Quando encerrou o mandato recebi ligações de todas as regiões brasileiras pedindo para empenhar esforços para continuar. 0 estatuto do CNPq não permitia a recondução (Depoente 3).

Neste depoimento vê-se a prerrogativa do Conselho Deliberativo em decidir a escolha. A quarta depoente também eleita pela comunidade científica, por duas vezes, foi indicada pela Presidência em dois períodos:

Exerci a função de representante da Área de Enfermagem no CNPq de 07/1995 a 07/1998. Como no período de atuação havia exercido o papel de Coordenadora do Comitê, no julgamento seguinte (11) 1998) fui também convocada para transmitir à equipe seguinte a memória do Comitê (CA-MS) integrado pelas áreas Odontologia, Enfermagem, Educação Física, Fisioterapia, Fonoaudiologia e Terapia Ocupacional. "Após um interstício de três anos, fui novamente indicada exercendo a representação no período de 07/ 2001 a 06/2004, também concluindo o mandato como coordenadora do Comitê (Depoente 4).

Vimos que o período de vigência mudou de dois para 3 (três) anos e foi marcado pela constituição e denominação dos comitês, trazendo uma terminologia que dava maior identidade às diferentes áreas do conhecimento que faziam parte do Comitê. A quinta depoente esteve no CNPq de julho de 1998 até julho de 2001:

Tive o prazer de atuar no Comitê Assessor

Multidisciplinar de Saúde que era constituído pelas áreas de Odontologia, Fisioterapia, Educação Física e Fonoaudiologia (Depoente 5).

\section{B) AS PRINCIPAISATIVIDADES COMO REPRESENTANTE} são destacadas nos depoimentos a seguir.

Ao assumir a representação em 1995, levei comigo a experiência de 13 anos como usuária do sistema, pois havia percorrido toda a carreira de pesquisador iniciada no ano de 1982 como mestre e aluna de doutorado. Portanto, em minha bagagem levei toda a vivência, dúvidas, inquietudes e a certeza de que a comunidade de Enfermagem carecia de estímulo e orientações precisas sobre as possibilidades de apoio aos seus projetos. Deste modo, considero que a principal atividade que exerci foi política, pois tinha convicção de que era preciso dar visibilidade do real desenvolvimento da Enfermagem como área de conhecimento aos responsáveis e integrantes da estrutura do órgão. A primeira ação, portanto, foi relatar ao Presidente o estado da arte da Enfermagem brasileira, oferecendo dados com a proposta de instrumentalizar o Conselho Deliberativo sobre o crescimento da área e da relação demanda versus reduzida oferta de recursos destinados à área em todas as modalidades de fomento. Do ponto de vista técnico, a principal atividade foi a emissão de pareceres que incentivassem os colegas a aprimorarem seus projetos e continuarem pleiteando. Ao lado disto, passamos a interagir com pesquisadores com 0 propósito de estimular o aumento da demanda para que se conseguisse ampliar a fatia de recursos para a Enfermagem no contexto do total que era destinado ao Comitê. No período de 2001 a 2004 conseguimos imprimir maior aproximação com os pares, praticando o exercício da conscientização da necessidade de união de esforços da maioria por mais espaço e recursos. Conseguiu-se assim, através de preleções em Escolas de Enfermagem que nos convidavam, assim como nos eventos promovidos pela classe, produzir significativo crescimento da demanda. Tais indicadores reforçaram os pleitos levados à presidência e à coordenadoria da saúde, justificando a ampliação de recursos, quotas de bolsas, de modo que a Enfermagem passou a receber expressivo aumento no investimento de projetos pelo CNPq (Depoente 4).

Neste depoimento relativo aos dois mandatos exercidos, observase 0 aumento da complexidade das atividades desenvolvidas e as conquistas da representação para a área de Enfermagem:

Ao assumir as atividades de representante da área da Enfermagem busquei conhecer mais de perto 0 órgão CNPq, sua estrutura, dinâmica de funcionamento, políticas e, em especial, as pessoas, a equipe de técnicos, os diretores, os pares representantes e demais pessoas que circulam naquele órgão. Em especial, destaco o contato com a representante anterior, o qual foi muito importante para o reconhecimento das atividades inerentes a essa representação. Também, a recepção do Presidente e o acolhimento da equipe técnica foram marcantes. Ainda, se somou a vivência da evolução da pesquisa na área pela trajetória pessoal de quase três décadas em atividades na $P G$, publicação e orientação regular, atuação na Capes, enfim... Familiaridade com o julgamento de processos de produção de conhecimentos e formação de pesquisadores da área (Depoente 6).

A estrutura do CNPq consolida experiência de funcionamento desde o ano de 1951. A presença das representantes de área é sentida como de suma importância, de reconhecimento e valorização do seu domínio e, ainda, competência na área que representa ${ }^{8}$. As atividades que realizam são descritas nos depoimentos a seguir:

Análise dos processos nas reuniões semestrais de julgamento; análise de processos emergenciais de grandes eventos da área. À época havia uma reunião durante a semana de julgamento com todos os coordenadores dos Comitês Assessores, ou seja, dos representantes de cada comitê, com o coordenador geral deste grande grupo e o presidente do CNPq; e 
elaboração dos relatórios das reuniões junto com os colegas de comitê, tentando inserir uma política mais agressiva nas nossas reivindicações (Depoente 5).

Estas atividades são mantidas nos dias atuais, como segue.

A representação inclui atividades diretamente no CNPq, tais como análise e julgamento dos processos relativos às diferentes modalidades de fomento que o órgão oferece mediante editais regulares e especiais, os quais são apreciados em reuniões periódicas dos membros dos CAS; análise de mérito de processos de fluxo contínuo; atividades externas junto à Comunidade Cientifica em eventos, visitas aos centros de pesquisa, e outros de caráter representativo no domínio da ciência, tecnologia e inovação da área da Enfermagem no país (Depoente 6).

Nos dois depoimentos citados, as atividades destacadas mostram a relevância do trabalho realizado, o que envolveu domínio de conhecimento sobre as bases teórico-filosóficas e epistemológicas que sustentam a área da Enfermagem como ciência, tecnologia, inovação; e competência política para conquista de espaço e reconhecimento da profissão no cenário nacional e internacional.

Incluem, também, a interface com as demais ciências, especialmente as da saúde, sociais e humanas, nas suas universalidade e especificidades, nos âmbitos regionais e internacionais. As discussões com os pares das demais áreas não se limitam à mera distribuição de recursos ou apoios para o desenvolvimento de atividades mais relevantes de cada área. Mas, na sustentação de políticas de desenvolvimento científico e tecnológico do país e sua projeção internacional, que possibilitem ganhos ou retornos significativos para as necessidades sociais ou impactos internos, regionais ou nacionais. A visão mais abrangente e profunda da realidade de sua área, bem como das demais áreas, possibilita a integração e o diálogo mais enriquecedores entre os pares, em prol de decisões mais pertinentes e mais seguras.

\section{C) OS AVANÇOS OBTIDOS PARA A ÁREA}

\section{são descritos a seguir:}

Uma das depoentes considerou que os avanços obtidos passaram pela visibilidade da Enfermagem:

o principal avanço foi mudar o nome do Comitê Complementar para Comitê Multidisciplinar de Saúde. Ressalto que tive uma grande preocupação em julgar as solicitações de bolsas com imensa responsabilidade, tentando identificar e ajudar os expoentes de cada região brasileira, sem corporativismo ou preconceitos. Por exemplo, tentávamos levar em consideração que um pesquisador do Acre não dispunha das mesmas facilidades para começar sua carreira como dispunham os de São Paulo, naquela época pré-internet (Depoente 3).

0 avanço mais significativo, no meu entender, foi a credibilidade da área refletida no aumento expressivo de recursos para as três modalidades [de bolsa]: $P Q$ [produtividade], IC [iniciação científica], AT [apoio técnico]. Em relação a estas duas últimas modalidades, havia um considerável desnivel favorável à Enfermagem, em relação às demais áreas do Comitê. Isto graças à ação politica de seus representantes e à correspondente resposta da comunidade apresentando demandas. No dizer de integrantes do Comitê, representando outras áreas, a Enfermagem tinha "um PIBIC inteiro". E em termos de bolsas de Apoio Técnico havia para a Enfermagem, no mínimo, dez vezes mais quotas do que para as demais áreas somadas. Isto se deveu ao trabalho dos representantes que demonstraram à presidência do CNPq a especificidade da área (Depoente 4).

Outra depoente considerou os avanços assim:

As principais atividades que realizava e avanços para a área: Reuniões para julgamento, todas aprazadas, terminavam sempre com uma reunião do presidente com os coordenadores. Independente dessas reuniões, por duas vezes reuni-me com o presidente para solicitar aumento de bolsas tanto $P Q$ quanto IC e AT, visando um maior crescimento da Enfermagem na produção do conhecimento. Nesta reunião estavam presentes a representante do período anterior, a atual (1998 a 2001) e a presidente do CEPEn/ABEn - Nacional (Depoente 5).

Referindo-se à integração com os membros do Comitê, uma das representantes destaca:

Quanto à integração com os demais membros do Comitê só tive problemas com um; ele queria tudo para a sua área. Até nas pontuações para alguma decisão sobre percentual de aprovação, por exemplo, nos casos de Editais, se alguém da Enfermagem apresentasse maior pontuação, ele criava estratégias para tentar levar vantagens. Sempre o enfrentei, e a Enfermagem sempre conseguiu ganhar dentro da distribuição eqüitativa com as demais. As outras profissões para ele eram inferiores. Embora o CNPq não adotasse que a representante comparecesse aos eventos da categoria (se convidado o CNPq, iria um técnico), apresentava-me em todos e em três participei de mesas redonda falando das atividades na área e apelando para enviarem seus projetos mais de uma, duas vezes até conseguirem, afim de aumentar a demanda. (Depoente 5)

Não consideramos esta citação como expressão de conflito, mas como defesa e luta pela categoria afim de que a mesma angariasse o merecido:

O exercício da coordenação do Comitê por dois períodos foi muito salutar no sentido da integração, do reconhecimento e respeito à força da área Enfermagem por parte dos integrantes do CA-MS que nos elegeram por aclamação, o que permitiu imprimir maior visibilidade da área, de um lado aos integrantes da estrutura do CNPq e, de outro, aos integrantes dos demais comitês. Ressalta-se que, para algumas modalidades de investimento, só participavam os coordenadores; portanto, representar a Enfermagem e as outras áreas do CA-MS, além de ter sido um avanço, 
permitiu aumentar a visibilidade da Enfermagem. Ao lado desta conquista, contamos com a confiança dos representantes das outras áreas do Comitê, em relação ao nosso trabalho, refletindo-se em credibilidade para a Enfermagem (Depoente 4).

Com o passar do tempo, verifica-se cada vez mais o respeito e a confiança na Enfermagem como área, nafigura de suas representantes, de modo que elas passaram a ser acionadas e destacadas para outros tipos de julgamento fora do CA-MS, representando a Enfermagem, mesmo após o término de seus mandatos.

Nesse sentido, percebe-se o reconhecimento da competência e credibilidade da área e do profissional, o que é uma oportunidade para ampliar a visibilidade da área quando inserida em outros Comitês. É o que se depreende do depoimento a seguir:

A Enfermagem tem tido oportunidade de demonstrar sua competência também em outros Comitês. Nos anos recentes participei do julgamento do Edital para Doenças Crônico-degenerativas representando a Enfermagem, Odontologia e Educação Física. Eu era a única não-médica neste Comitê Específico. Nesta oportunidade fui convidada para coordenar um julgamento no Comitê de Bioética. A justificativa da convocação era a de que minha experiência em coordenação de Comitê precisava ser transferida para aquele [Comitê] recém-criado (Depoente 4).

Em retrospectiva, analisando-se a representação da Enfermagem no momento de sua inserção e sua evolução, evidenciase a atual marca conquistada em diferentes períodos, ou seja, a posição do CNPq em reconhecer que as representantes da Enfermagem poderiam e deveriam replicar suas experiências em outros Comitês. Um espaço de interações e associações entre pares, representantes de diferentes saberes, mas integrantes de uma grande área de conhecimento, é permeado por relações de força e de potencial crítico, reflexivo e argumentativo, num jogo do diferenciar e igualar ao mesmo tempo.

Na medida em que avançam as práticas interdisciplinares na saúde, reconhecendo o potencial de força, interdependências e domínios específicos das diferentes disciplinas ou profissões da saúde, essa religação de saberes não admite mais a soberania ou a arrogância de uns sobre outros, e sim atitudes político-sociais na soma de esforços para conquistas maiores, co-responsabilidade pelos avanços e necessidades da sociedade demandadas pelo trabalho do coletivo de pesquisadores da área da saúde ${ }^{2,8}$.

Além dos avanços em relação às experiências de representação e coordenação das representantes da Enfermagem, destaca-se, também, o aumento significativo do número de pesquisadores com bolsa de produtividade. Em 1991 contávamos com 49 doutores pesquisadores no sistema do $\mathrm{CNPq}^{4}$. Este número foi aumentando à medida que as representantes da área insistiam, negociavam e solicitavam aumento das cotas. Assim é que, em 1998, já contávamos com 80 cotas (depoente 4). Em 2001, a Enfermagem estava com 90 cotas (depoente 5). E hoje são 111 doutores pesquisadores no CA-EF (depoente 6).

Assim como o número de pesquisadores cresceu, maior ainda foi o crescimento qualitativo, tomando-se em conta que em 1991 era um (1) pesquisador IA; em 1993 eram três (3) pesquisadores IA. E hoje são nove (9) pesquisadores neste nível e categoria. A proporção entre pesquisadores que atingiram o nível mais alto $(\mathrm{IA})$ e o número de pesquisadores cadastrados (111) ainda não é a ideal, pois aponta para uma concentração de pesquisadores de categoria/nível 2 . Possivelmente, isto resulta da produtividade dos pesquisadores, os quais não estão conseguindo manter a regularidade da publicação de qualidade e, também, não estão suficientemente envolvidos com a formação de recursos humanos de pós-graduação (mestrado e doutorado) e de iniciação científica, para assim atender às exigências do órgão, para fins de progressão ${ }^{9}$. Por outro lado, os mecanismos internos da agência também poderiam estar contribuindo tanto para um crescimento maior do número de bolsas de produtividade concedidas como para progressão dos próprios pesquisadores nos níveis/categorias do órgão.

Registramos ainda como avanço a mobilização feita junto ao CA-MS, no sentido de conquistar a criação de mais dois novos Comitês, um para a Enfermagem e outro para a Odontologia, o que aconteceu em 2005. Assim:

Ao perceber a já expressiva demanda de projetos e as dificuldades na partilha das quotas entre as subáreas no CA-MS, sondou-se junto à equipe técnica a viabilidade de infra-estrutura interna para a criação de novos comitês. Assim, partiu-se para a mobilização desta idéia mediante a elaboração de uma carta junto com a Coordenadora do CA-MS, representante da Odontologia, no último dia da reunião de trabalho, ou seja, em 11 de março de 2005. Esta carta foi assinada por nós duas e enviada ao Presidente. Também nesta ocasião, fizemos uma reunião com diretores expondo ... nossas necessidades, sendo amplamente apoiadas. A expectativa era pela criação de mais dois Comitês. Em maio, por ocasião da análise dos processos para reclassificação dos $P Q$ [bolsas de produtividade], apresentamos critérios de análise já específicos para cada área: Odontologia, Enfermagem, e demais áreas. Embora o número de bolsistas de Produtividade da Odontologia e Enfermagem sejam bastante próximos, de 136 e 111 [respectivamente], há significativa diferença na média da pontuação dos currículos, o que é resultado de publicações em periódicos mais qualificados, que possibilitou à Odontologia criar critérios levando em conta o índice de impacto dos periódicos. A área da Enfermagem ainda não possui este perfil de publicações internacionais e consolidação como ciência e tecnologia. Assim, em julho de 2005 é criado um novo comitê CA-Odontologia, o que liberou espaço no CA-MS na competitividade das quotas e, do mesmo modo, propiciou um destaque para a Enfermagem no comitê em que permanece abrindo caminho para novas tentativas de emancipação na luta por um CA [da] Enfermagem (Depoente 6).

A pesquisa tem sido uma área de contínuo crescimento e investimento por parte da Enfermagem Brasileira. 0 caminho 
percorrido até o patamar atual foi longo e muito difícil. 0 Primeiro Congresso Brasileiro de Enfermagem (I CBEn), realizado em 1947, recomendou que as Enfermeiras se iniciassem na pesquisa. Em 1964, o tema central do XIV CBEn foi "Enfermagem e Pesquisa", por sugestão da coordenadora da Comissão de Temas, Prof́. Dra. Maria Ivete Ribeiro de Oliveira, da Escola de Enfermagem da Universidade Federal da Bahia, de saudosa memória8.

A partir do ingresso da Enfermagem no Sistema Nacional de Pós-graduação, a pesquisa tomou vulto com o início do seu primeiro curso de mestrado em 1972, na Escola de Enfermagem Anna Nery da Universidade Federal do Rio de Janeiro. Paralelo a isto, outras Instituições criaram os seus cursos de pós-graduação stricto sensu. Hoje, A Enfermagem conta com 29 Programas de Pós-Graduação em Enfermagem no país, dos quais doze possuem o nível de doutorado ${ }^{10}$.

Os avanços são percebidos nos Programas de PósGraduação, considerados os maiores centros de produção de conhecimento científico, cuja prática de pesquisa em Enfermagem tem crescido qualitativa e quantitativamente. 0 aumento do número de Programas, bem como do volume e qualidade das publicações leva a um maior interesse pela pesquisa e busca de fomento. A demanda cada vez maior de solicitações de apoio do CNPq é resposta à necessidade de intensificar a produção de conhecimento nos Programas de Pós-Graduação, bem como de obter bolsas de formação (Mestrado, Doutorado, Pós-doutorado, Doutorado Sanduíche) e bolsas de iniciação científica e apoio técnico para os projetos de pesquisa dos doutores pesquisadores.

D) A EXPERIÊNCIA DE SER REPRESENTANTE é mostrada nos depoimentos a seguir:

A experiência de ser representante teve aspectos bons e outros limitantes. Os positivos são relacionados à oportunidade de conhecer líderes e a produção de conhecimentos da área de Enfermagem no território brasileiro (Depoente 3).

A prática de análise de projetos ou de solicitações demandadas ao órgão propicia uma visão geral dos pesquisadores da área, do perfil de produtividade dos mesmos, das tendências de temáticas e métodos investigados, dos produtos obtidos e de sua distribuição nas diferentes regiões do país, bem como dos vazios e impropriedades encontradas ${ }^{11}$.

Outro aspecto foi a oportunidade e prazer em pensar as questões acadêmicas com maior responsabilidade, o que foi enriquecido pela troca de experiência com colegas consultores Ad Hoc (Depoente 3).

0 aprendizado na leitura dos pareceres dos consultores ad hoc e seu confronto com as propostas analisadas é impar, motivante e desafiante, abrindo para a busca de inovações e diversidades de olhares na construção de conhecimentos da área:

Outro fato foi vivenciar um momento de crescimento dos pesquisadores e da área, incentivando o aumento da demanda, numa época em que tínhamos mais liberdade pessoal para julgar segundo critérios qualitativos, e não apenas quantitativos (Depoente 3).

0 domínio dos critérios de análise, no sentido de julgar o mais corretamente possível os pedidos de fomento, passa pela estrutura definida de caráter quantitativo, somando-se aos aspectos qualitativos. Todavia, os aspectos quantitativos determinam os pontos de corte. Assim, quer qualitativo, quer quantitativo, após atender os critérios legais técnicos, 0 mérito referente ao conteúdo, pertinência, coerência e sustentabilidade da proposta e a capacidade produtiva do proponente, busca-se cercar a viabilidade da proposta com condições que assegurem a possibilidade de retorno significativo para a sociedade. Trata-se, portanto, de um exercício atentivo de análise de solicitações dentro da área com um olhar para as demais áreas que compartilham 0 Comitê. Esta é uma liderança de autonomia relativa e compartilhada. Assim:

Os pontos limitantes foram mais relacionados ao pequeno número de bolsas em relação à oferta, resultando em situação dramática para a inserção dos novos doutores. Esses, muitas vezes com grande potencial para a pesquisa, tinham que ser preteridos em função de seus próprios orientadores, muitas vezes pessoas brilhantes, continuamente convidadas para falar em eventos (Depoente 3).

Não há dúvida que o potencial para a pesquisa cresce numa proporção muito maior do que a oferta de cotas para atender a demanda. A qualidade das propostas analisadas e a produção mais qualificada dos pesquisadores da área são uma realidade:

A experiência como pessoa e como profissional considero excelente, apesar das reclamações dos pares que solicitavam bolsas e não conseguiam. É um aprendizado ímpar. Na verdade, a demanda sempre foi maior que as cotas destinadas para a área. Sempre entendi a representação como uma maneira de mostrar que a Enfermagem existe como profissão caminhando para a Ciência. Das conquistas, consegui, embora um pequeno número, aumento das cotas. E acredito que a demanda aumentou também. Além da divulgação da área que sempre procurei fazer e auxiliar ao máximo a quem gostaria de pedir $P Q$. Durante o mandato, três presidentes passaram pelo CNPq; o primeiro, o Prof. Tundizi (da UFSC/São Carlos), aumentou nossas cotas e nos entendeu, ou melhor, compreendeu o que é a Enfermagem e parecia gostar de conversar conosco sobre a nossa profissão (Depoente 5).

A necessidade de conviver com as insatisfações de quem não teve suas solicitações contempladas leva a um sentimento de serenidade pela consciência dos limites existentes, e, ao mesmo tempo, vislumbram-se outras possibilidades de demanda em órgãos de fomento ou fontes de recursos que pouco tem sido explorados.

Existe o reconhecimento de que a produção de conhecimentos necessariamente requer recursos financeiros, 
humanos, físicos, materiais, logísticos, políticos e outros. A competitividade leva à busca de múltiplas tentativas. E este é um fenômeno que se dá em todas as áreas de conhecimento que, desde logo, marcaram presença em outras agências com a mesma força que se mostrou no CNPq. Parece que a Enfermagem Brasileira carece agora desta compreensão e de mais assertividade na busca de outras alternativas a serem exploradas simultaneamente com as propostas submetidas ao CNPq.

A experiência vivenciada, ao atuar no órgão exercendo o papel de representante, avaliando os processos e os pareceres ad hoc e, ao mesmo tempo, interagindo com os pares que submetiam projetos, nos permitiu uma visão mais abrangente da situação da Enfermagem, de sua evolução, de suas perspectivas e limitações. Se os representantes muito bem convenceram a comunidade sobre a importância de ter sempre uma demanda elevada, precisam agora atuar no sentido de busca de espaços tanto para representação da Enfermagem em outros órgãos (Fundações de Apoio à Pesquisa em cada Estado, por exemplo), como de direcionamento de projetos demandando recursos em outras fontes. $A$ capacidade de crescimento do CNPq é limitada para todas as áreas. Devemos manter nossa presença, buscar sempre a melhoria do perfil científico dos pesquisadores e da qualidade dos projetos, mas urge que outros espaços sejam também conquistados, para garantia de recursos à pesquisa e à transferência dos resultados aos serviços (Depoente 4).

A análise da Enfermagem pelas agências, como profissão e ciência, revela algumas conquistas, aumento da demanda de doutores. Porém, é preciso avaliar o real significado que tem para agências, aquilo que consideramos "conquistas". E é preciso avaliar o real significado para a sociedade. Que conhecimentos foram caracterizados, aprofundados, resultando em melhores condições para os sujeitos de nossas ações? Acredito que temos grande potencial para direcionarmos melhor nosso trabalho para adquirir conhecimentos que beneficiem mais objetivamente a sociedade e identificar focos de interesse. Por exemplo, tenho certeza que, se um grande contingente da Enfermagem estivesse voltado para buscar conhecimentos que melhorassem a qualidade de vida e atenção dos portadores de problemas oncológicos, certamente seríamos muito respeitadas.

\section{Referências}

1. Méis L. 0 perfil da ciência brasileira. Rio de Janeiro (RJ): UFRJ; 1996.

2. Leite JL, Mendes IAC. Pesquisa em enfermagem e seu espaço no CNPq. Esc Anna Nery Rev Enferm 2000 dez; 4(3): 389-94.

3. Wright MGM. A imagem do enfermeiro e da profissão de enfermagem veiculada ao público. Anais do $1^{\circ}$ Simpósio Brasileiro de Comunicação em Enfermagem-SIBRACEn 1988 maio 2-4; Ribeirão Preto(SP). Brasil. Ribeirão Preto (SP); 1988. p. 525-601.
Muitas de nossas pesquisas não vêm sendo bem compreendidas, e, se quisermos defendê-las, precisamos dar respostas bem fundamentadas, seja qual for 0 referencial teórico-metodológico, etc, etc (Depoente 3).

Assim como as enfermeiras cresceram em qualidade e quantidade na prática investigativa, por outro lado, vazios de conhecimentos são perceptíveis, e as cobranças também são freqüentes. 0 impacto do que produzimos requer uma constatação mais precisa, como também a necessidade de dar conta das prioridades da saúde, de produtos tecnológicos que propiciem uma resposta mais incisiva na melhoria da qualidade de vida, e mesmo de inovação que dê retorno econômico mais expressivo. 0 benefício econômico e social dos conhecimentos produzidos e aplicados na prática da Enfermagem é ainda um desafio para os gerentes das práticas investigativas na área da Enfermagem.

Estes depoimentos mostram alguns aspectos relativos às vivências e experiências das representantes na sua representação, bem como as perspectivas de mudança que nos apontam.

\section{CONSIDERAÇÕES FINAIS}

As informações descritas possibilitaram, de certo modo, mostrar a importância e a evolução da Enfermagem como ciência e tecnologia e, ainda, a importância do fomento para viabilização das pesquisas, o estímulo ao incremento da pesquisa, os avanços na produção de conhecimentos, os desafios enfrentados e as perspectivas como possibilidades para o fortalecimento e consolidação da Enfermagem ${ }^{11}$. 0 desenvolvimento da pesquisa é uma importante estratégia para o fortalecimento da Enfermagem como ciência e profissão. E o CNPq é um importante órgão de fomento às políticas para 0 avanço da Enfermagem.

Neste estudo, vimos que as profissões de saúde possuem algum tipo de identidade coletiva, e existem peculiaridades que pertencem a uma distinta categoria profissional. Os comportamentos, os conhecimentos e as práticas próprias de cada categoria revelam uma cultura profissional específica. Neste sentido, percebe-se que as relações não estão expressas objetivamente. Elas são intersubjetivas, perpassando nas entrelinhas das relações por meio de expressões que não são mensuráveis, nem essencialmente abstratas ${ }^{12}$.

Desta forma, este estudo traz dados sobre a presença da representação da Enfermagem no CNPq, que vem fazendo parte da História da Enfermagem Brasileira.

4. Barreira IA. A pesquisa em enfermagem no Brasil e sua posição em Agência Federal de Fomento. Rev Latino- Am Enfermagem 1993 jan; 1(1):51-7

5. Leite JL, Mendes IAC, Felli VE, Trezza MCF, Santos RM. Os projetos de pesquisa de enfermagem no CNPq: seu percurso, suas temáticas e suas aderências 1988-2000. Rev Bras Enferm 2001 jan/mar; 54(1): 81- 97.

6. Ministério da Ciência e Tecnologia (BR). Informativo Eletrônico do Comitê Assessor de Enfermagem-CNPq/CA-Enf.[on-line] 2006 dez; 5(2). [citado jun 2005]. Disponível em: http://www.cnpq.br. 
7. Ministerio de Ciência e Tecnologia (BR). Conselho Nacional de Pesquisa.[on-line] [citado jun 2005]. Disponível em: http:// www.cnpq.br

8. Mendes IAC, Leite JL, Trevizan MA, Santos RM. Classificação dos pesquisadores/consultores da área de enfermagem no CNPq: contribuição para um banco de dados. Rev Bras Enferm 2003 set/ out; 56(5): 488-93

9. Gutierrez MGR, Leite JL, Erdmann AL, Pagliuca LMF. Os múltiplos problemas pesquisados e a pesquisar na enfermagem. Rev Bras Enferm 2002; 55(5): 535-41

10. Erdmann AL, Rodrigues RP, Silva IA, Fernandes JD, Santos RS, Araújo TL. A formação de doutores em enfermagem no Brasil. Texto\&Contexto Enferm 2002;11(2): 66-76

11. Mendes IAC. Pesquisa em enfermagem: impacto na prática. São Paulo(SP): EDUSP; 1991.

12. Prochnow AG, Leite JL, Erdmann AL. Teoria interpretativa de Geertz e a gerência do cuidado: visualizando a prática social do enfermeiro. Rev Latino-Am Enfermagem 2005 jul/ago;13(4): 583-90.

\section{Sobre as Autoras}

\section{Alacoque Lorenzini Erdmann}

Enfermeira. Professora Titular e Coordenadora do GEPADES / UFSC. Representante da área de Enfermagem no CNPq Gestão 2004-2007. Coordenadora do Comitê Multidisciplinar de Saúde 2005 a 2006 e do Comitê Assessor de Enfermagem 2006 a 2007. Pesquisadora 1A / CNPq.E-mail alacoque@newsite.com.br.

\section{Isabel Amélia Costa Mendes}

Enfermeira Professora Titular da Escola de Enfermagem de Ribeirão Preto / USP - Centro Colaborador da Organização Mundial de Saúde para a Pesquisa em Enfermagem. Representante da área de Enfermagem no CNPq e Coordenadora do Comitê Assessor Multidisciplinar de Saúde gestão 1995 a 1998; e 2001 a 2004. Pesquisadora 1A / CNPq.

\section{Joséte Luzia Leite}

Enfermeira aposentada. Professora Titular e Professora Emérita / UNIRIO. Membro da Diretoria do Núcleo de Pesquisa, Gerência, Exercício Profissional da Enfermagem (GESTÃO da EEAN). Ex-representante da área de Enfermagem no CNPq Gestão 1998 a 2001. Diretora do CEPEn / ABEn Nacional. Pesquisadora 1A / CNPq. E-mail joluzia@gmail.com.br. 